\title{
What is good medical ethics? A very personal response to a difficult question
}

\author{
Bobbie Farsides
}

\section{Correspondence to} Professor Bobbie Farsides, Department of Medicine, Brighton and Sussex Medical School, University of Sussex, Brighton UK ST5 9PX, UK; b.farsides@bsms.ac.uk

Received 28 October 2014 Accepted 29 October 2014

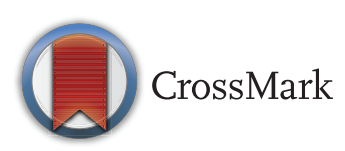

To cite: Farsides B. J Med Ethics 2015;41:52-55.

\begin{abstract}
A personal reflection upon a career in medical ethics leads to four conclusions on what makes for 'good medical ethics'. Good medical ethics is practical in approach, philosophically well grounded, cross disciplinary, and while it might not be a necessary feature, the experience of the author suggests that it is the work of 'good people'.
\end{abstract}

What is good medical ethics? I've agonised over this question and changed my mind several times about how best to respond to it. But now the time has come when pen must be put to paper and thoughts be translated into some sort of position that I am prepared to at least own, if not defend. I have decided to give a very personal account of what it means to me to do good medical ethics with the hope that it will resonate with some readers. I do this not only because I feel best qualified to speak for myself on this matter, but also because I have become increasingly interested in the power of personal narratives, and this is an opportunity to explore and share my own account of the work I do and the world I professionally inhabit.

Many people reading this celebratory edition will appreciate the potential to see a trick in the question posed-medical ethics has meant different things to different people at different times, and lately the use of the word 'medical' has been challenged as too limited in scope and perhaps a bit old fashioned. However, I'm not going to enter that debate, I am comfortable with saying I do medical ethics because people tend to know what it means in broad terms, and to be honest the alternatives have their own problems. I am also comfortable, in a way that some people are not, to call myself an ethicist, and I will use that label to identify myself as someone who attempts to do the work of medical ethics.

For me medical ethics is more than an academic or intellectual discipline with an accompanying body of literature. Rather it is a form of practice directed towards identifying and addressing problems which are rarely if ever purely theoretical or predominantly conceptual. As such I believe that those of us who call ourselves medical ethicists are motivated by something beyond intellectual curiosity. We do the work of medical ethics in order to make a difference in the world, and I further believe that to do 'good medical ethics' we must be prepared to work outside the traditional academic environment within which many of us grew up because that is where we can be most hopeful of making some sort of practical difference.
Our role is often to help others recognise the nature of the ethical problem or problems they confront in the hope that they can then find ways to solve them in a manner consistent with their professional goals and values. A good medical ethicist does not set out to be a super-hero. Rather an ethicist is a facilitator or guide, the person who gives others the vocabulary, analytical tools and framework within which to resolve their own issues.

As a practical discipline born of moral philosophy, medical ethics is directed towards addressing the fundamental (and the more everyday) ethical questions as they arise in the healthcare setting. Clearly philosophers have been addressing the core issues of medical ethics for many years; long before a discrete discipline was formally acknowledged they had considered the issues of life and death, distributive justice, issues of capacity and identity, and many of the difficult questions we still seek to resolve. Some of the words written in those early days have incredible staying power and I would choose still to share these works with an interested student or clinical colleague. There are seminal texts which helped to define our field, introductory books which carefully guided practitioners into philosophical waters, and iconic articles many of which were written by pioneers who will be familiar to any JME reader and whose contributions continue to be valued and enjoyed. ${ }^{\mathrm{i}}$

Over time a community has grown that is now global in membership and reach, and one of the features of that community is the diversity of interpretation and approach to medical ethics. Global bioethics has challenged the dominance of an Anglo-American model, while feminist bioethics has been invaluable in reshaping our understanding of some core conceptual issues. However, I believe it is possible to make some foundational statements about the discipline of medical ethics and how it operates when it works well.

${ }^{\mathrm{i}}$ These are books I read in the very early days of my career, still turn to now, and which I will often recommend to those new to our field. Glover J. Causing Death and Saving Lives. London: Pelican Books, 1977; Singer P. Practical Ethics. Cambridge: Cambridge University Press, 1979; Harris J. The Value of Life. London: Routledge \& Kegan Paul, 1985; Gillon R. Philosophical Medical Ethics. Chichester: Wiley \& Son, 1985; Lockwood M. Moral Dilemmas in Modern Medicine. Oxford: OUP, 1985; Hursthouse R. Beginning Lives. Chichester: Wiley Blackwell, 1987; Dworkin G. The Theory and Practice of Autonomy. Cambridge: Cambridge University Press, 1988; McNaughton D. Moral Vision. Oxford: Blackwell, 1988; Dancy J. Moral Reasons. Chichester: Wiley Blackwell, 1992. 
Behind every interesting medical ethical issue lies the fundamental question of what an individual or some institution ought to do, or perhaps how some person (or professional group) ought to be like in terms of motivations, goals, characteristics and virtues. Being a good doctor is now defined not only in terms of technical skills and know-how, rather it is about being the right sort of person to do the job and it is about constructing an environment and moral framework within which that is possible-'the job' being much more than making people better.

One could argue that medical ethics has only been able to develop as an academic discipline because medicine itself has undergone substantial change. Medicine is no longer described or understood in terms of the necessarily reductionist 'medical model', or if it is that is understood to be a problematic limitation. Instead we appreciate that medicine and the medical encounter is a product of the culture within which it exists, and that doctors need to understand and in turn challenge, nurture and/or shape that culture. Acknowledging the complexity of modern medicine and its inevitable connectedness to other aspects of modern life has led those within the profession to be more welcoming of the work that others can do to help them understand and perform their role as doctors.

I choose not to enter a debate around whether it is ethics that has shaped modern medicine, or whether evolving modern medicine has created the space for and essentially generated a need for medical ethics. This is not of major concern to me, but I do want to acknowledge that at the same time as our understanding of medicine has become much more sophisticated, our belief that ethics is an integral part of modern medicine has become less contested. Many of us work in medical schools because the medical profession's own regulatory body decided some years ago that ethics should be a continuous strand through undergraduate medical education. ${ }^{1}$

Characterising medical ethics as a substantially practical discipline has implications for the ways in which I and others choose our audiences and then try to gain their attention. While I personally retain a pathetic desire to convince my philosopher friends that I haven't lost the commitment to 'do sound work' in terms they acknowledge and respect, they are not my audience. While I still enjoy the challenge of honing my skills of analysis and debate in the conference hall and seminar room, when I put my work into the public arena I care most about communicating in a way that is accessible and helpful to those who confront the problems I am examining. If I'm doing medical ethics, as opposed to moral philosophy, I want my work to speak to those who are 'doing the day job' or 'living through the experience'.

Holding this view also has interesting implications for where and how I 'do' medical ethics. As an esteemed colleague recently claimed we might do better presenting carefully crafted sound bites during a 3-min slot on BBC's Radio 5 Live than by competing to fill the pages of a journal such as this. However, the same colleague could say confidently that those who were interested in accessing his deeper thoughts could easily trace a huge body of scholarly work. At a recent meeting on research impact another colleague presented convincing evidence of the power of social media in helping academics reach both their peers and wider audiences. ${ }^{2}$ In Brighton, where art, culture and performance are woven into the fabric of the city, we at the local medical school have found members of the artistic community invaluable allies and collaborators in helping us reach local, national and international audiences.

At a time when British universities are getting used to making the case for the impact of their researchers' work, ethicists have been able to come to the fore. These developments please and to some extent excite me. Those of us who do medical ethics increasingly have the opportunity to combine traditional scholarship with practical hands on involvement in practice development, policymaking, governance, and public and community engagement, and in the new academic environment this outward looking approach is something the universities will value and hopefully benefit from encouraging. Ethics is engaging, and the public respond enthusiastically to being brought into the debates of the day. At the same time, those charged with affecting change in our society are increasingly aware of the need for a sound moral compass to guide policy and to give the public the confidence to come on side.

\section{CONCLUSION 1: GOOD MEDICAL ETHICS IS A PRACTICAL DISCIPLINE THE PRODUCTS OF WHICH CAN BE INTERESTING AND USEFUL TO WIDE AND DIVERSE AUDIENCES}

In part due to the new outward looking approach of universities the work I do now is dramatically different from when I originally set out to become a political philosopher. In the early days of my career my natural environment was the library (in fact I spent many years in the manuscript room of the old British Library) and beyond that the space I inhabited still resembled the now largely non-existent ivory tower. I was fortunate in that I was happy, indeed anxious, to break out of this environment and emerge into the 'real world', hence my attraction to medical ethics when it became an option in the mid-1980s. However, I had spent enough time in this world to understand its value and importance, even if I did not particularly want to stay within it.

For me, one of the partnerships key to good medical ethics is between those who stay within philosophy departments and those whose work leads them to relocate. I would defend the right of my ex-colleagues to work in a world where success can sometimes be measured in terms of the right five people reading and respecting your work. I am touched by the intellectual mentorship I have seen over the years, the way in which older and younger generations of philosophers ensure that great debates continue and the finer points of the matter do not get overlooked.

There is space within academe for great minds having great ideas, and we need to continue to train young minds in the skills, the joys and the pains of philosophy. However at the same time we must avoid and/or challenge the idea (prevalent early on in my career) that applied ethics in general and medical ethics in particular is forever committed to being 'philosophy light'. Instead I would argue that doing good medical ethics involves retaining a commitment to sound philosophical scholarship while taking on the additional responsibilities that come with doing medical ethics. Good medical ethics is actually 'philosophy plus'.

To be clear, I have encountered some of the finest minds it has been my privilege to meet within the world of medical ethics. If done well it is indistinguishable from the best of moral philosophy. A commitment to do practically applicable work does not mean that the medical ethicist is incapable or unwilling to engage with those who remain within the world of philosophical discourse as opposed to praxis. I read and enjoy the latest philosophical works when I have the time, and remaining connected bolsters and/or challenges my way of thinking. I may return to the company of philosophers from time to time to make sure my chosen theoretical approach still makes sense, I will listen in on certain meta-ethical conversations to feed my 
sentimental attachment to a particular form of moral realism, and (if I'm feeling brave) I will sharpen my tools from time to time by re-entering the philosophical bear pit.

Medical ethicists need philosophers rather in the same way as Catholic parish priests need members of contemplative orders. I want to continue to be able to talk with my philosophical colleagues, but I chose a different path and I am no longer of their ilk. ${ }^{3}$ Equal but different, my new academic heroes are colleagues in medical ethics who can 'turn it on when they want to' but like me prefer to apply philosophical abilities outside and beyond academe. I aspire to be like the best of them, but alas my bookshelves groan under the weight of all the books I still need to read to get there. What we can and should do together is challenge any sense that the philosophical grounding for medical ethics is set in stone, or even more worryingly is accessible to anyone through the reading (or second hand consumption) of one influential text. ${ }^{4}$

\section{CONCLUSION 2: GOOD MEDICAL ETHICS REMAINS LINKED TO OTHER BRANCHES OF PHILOSOPHY IN THE INTERESTS OF ENSURING THAT THE PRACTICAL FOCUS OF THE WORK IS ENRICHED BY ROBUST PHILOSOPHICAL ROOTS}

One of the ways in which medical ethics has developed in a distinctive manner is in its embrace of inter-disciplinarity. Early on this could have been more by accident than design, as for a couple of decades it felt as if we were a discipline in the process of inventing ourselves, and as such we welcomed all comers and tried to make sense of how to work together. Over time we have learnt the substantial benefits of working closely with those in the sciences, social sciences, and humanities and of course colleagues with clinical experience and responsibility. This makes perfect sense if you accept my initial assertion that medical ethics is a practical discipline directed towards addressing issues in the real world, and it works particularly well if, like me, you believe that ascertaining and then analysing the facts of a matter is crucially important to establishing the ethically appropriate response to any issue arising.

I was recently accused of having become a sociologist. I'm not sure it was meant as a compliment, hence my use of the term accused, but I was neither concerned nor upset. Rather I was reminded of the fact that because good medical ethics is rarely mono-disciplinary, medical ethicists have over time become the new polyglots, a development that holds its own dangers if we thereby become Jack of all trades and master of none.

In the past decade we have embraced the term empirical medical ethics to accommodate the fact that many of us are now involved in empirical work utilising social scientific methodologies and collecting and analysing data. This development has been encouraged in large part by the generous funding offered by bodies such as the Wellcome Trust, but this development has not been unproblematic. Some social scientists have questioned the ability, and to some extent the right, of ethicists to stray into 'their' area of research. ${ }^{5}$

This opposition aside, I feel confident to claim that in its best forms the development of empirical bioethics has led to new and enduring collaborations which have enriched all the specialties involved. And so, in recent years doing good medical ethics has led me to spend more time with sociologists and anthropologists, lawyers and practitioners than philosophers. For the philosophical elements of medical ethics you can go it alone, for the empirical component the clue to success lies in multidisciplinary collaboration.

In my own case I have benefitted hugely from a long-term collaboration with medical sociologist Clare Williams, a relationship which would never have developed had the pioneering sociologist/activist Priscilla Alderson not brought us together on the very first Wellcome Trust funded bioethics project back in 1999. Our early collaboration was quite challenging - and we have reflected upon this at the time and since; ${ }^{6}$ but over time sustained contact has helped us to develop and fine tune our methodological approach, and to conduct a series of projects which have contributed to an understanding of what it means to work in ethically contested fields of biomedical science and medicine. This in turn has provided evidence and developed forms of understanding which have contributed to the development of professional practice and public policy across a range of important issues. I offer this example not to claim that we do particularly good medical ethics-that is for others to judge- but rather to illustrate that it is possible to do work that will make a real difference both directly and indirectly when adequately supported to do so. The data collected in our empirical studies have been of value in their own right, but have also been invaluable as a trigger to substantive normative and theoretical analysis.

While some claim that empirical medical ethics is little more than the social scientific study of medical issues that are ethically interesting, I would make a stronger claim and argue that (done well) empirical ethics is a form of social scientific enquiry which helps us to identify and share knowledge about the ethical landscapes that practitioners inhabit. As such it is an invaluable tool for those who seek to identify and address ethical issues of true relevance to medically focused audiences. And given my personal meta-ethical take, I would further argue that it is an essential reference point for those seeking to do sound normative analysis. At its best it is a form of action research which can engage participants in ethical reflection and critical debate, and potentially effect change within institutions and inform policymaking at the highest level.

\section{CONCLUSION 3: GOOD MEDICAL ETHICS IS WELL FUNDED MEDICAL ETHICS WHICH ALLOWS FOR CROSS DISCIPLINARY COLLABORATIVE RESEARCH TO BE CONDUCTED IN 'REAL WORLD' SETTINGS}

In the most recent era of my career I have acquired a new set of colleagues whose natural environment is the committee room, government departments, professional bodies, and even the legislative chambers. At the same time I have had the privilege and pleasure to work with bodies such as the Nuffield Council on Bioethics whose mission is in large part 'To identify and define ethical questions raised by recent advances in biological and medical research in order to respond to, and to anticipate, public concern'. ${ }^{7}$ In this context I have shared space with scientists and clinicians at the height of their professional careers who have taught me so much and who in turn have listened to my take on their world and the issues they are grappling with. Together we have dealt with some really big issues, and this work is among that of which I am most proud. However, the greatest lesson that I have learnt from this phase of my career is that good medical ethics is about the efforts of good people. Looking back over my career this conclusion should not come as a surprise as good people have been there all along, so I shall finish this personal account in a very risky way, by presenting a list of good people I have had the pleasure to work with and be inspired by.

My career would not have been the joy that it has been and still is without John Rogers, Jonathan Dancy, David McNaughton, Tom Farsides, Jonathan Glover, John Porter, Raanan Gillon, Roger 
Higgs, John Harris, Margot Brazier, Alistair Campbell, Tony Hope Priscilla Alderson, Clare Williams, Heather Draper, Stephen Wilkinson, Becki Bennett, Charles Erin, Mike Parker, Richard Ashcroft, Don Rogers, Ann-Marie Slowther, Anneke Lucassen, Jose Miola, Penney Lewis, Rosamund Scott, Sara Fovargue, Sue Eckstein, Deborah Bowman, Veronica English, Julian Sheather, Mark Bale, Triona Noman, Peter Jones, Elisabeth Buggins, Chris Rudge, Peter Simpson, Susi Bull, Anna Dumitriu, Marilyn Strathern, Jonathan Montgomery, Hugh Whittall, Katharine Wright, Kate Harvey, Pat Spallone, Dan O’Connor, Paul Woodgate, Clare Matherson, Jon Cohen, Michael Farthing, Julian Crampton, Kevin Davies and all my wonderful colleagues at Brighton and Sussex Medical School (too many to name) who welcomed and supported me from the outset, and who have come to understand what this ethicist within their midst is all about. My hope is that together we have been able to do some good medical ethics and with luck we will go on to do more. I therefore finish with my most personal of conclusions, drawn from nearly 30 years in this field.
CONCLUSION 4: GOOD MEDICAL ETHICS IS ABOUT GOOD PEOPLE

Competing interests None.

Provenance and peer review Commissioned; internally peer reviewed.

\section{REFERENCES}

1 General Medical Council. Tomorrow's doctors: outcomes and standards for undergraduate medical education. London: GMC, 2009.

2 Bastow S, Dunleavy P, Tinkler J. The impact of the social sciences: how academics and their research make a difference. London: Sage Publications, 2014. ISBN 9781446275092.

3 Carol Shields 'Ilk' in Dressing up for the Carnival Fourth Estate 2003.

4 Beauchamp T, Childress J. Principles of biomedical ethics. 7th edn. New York: Oxford University Press, 2013.

5 Hedgecoe AM. Critical bioethics: beyond the social science critique of applied ethics. Bioethics 2004;18:120-43.

6 Williams C, Alderson P, Farsides B. Interdisciplinary research: culture clash or the best of all worlds? In: Hallowell N, Lawton J, Gregory S. Reflections on research: the realities of doing research in the social sciences. Open University Press, 2004:35-45.

7 The Nuffield Council on Bioethics. http://nuffieldbioethics.org/about 